\title{
Assessment of Patients with Chronic Obstructive Pulmonary Disease
}

\author{
Barry J. Make ${ }^{1}$ and Fernando J. Martinez ${ }^{2}$ \\ ${ }^{1}$ Division of Pulmonary Sciences and Critical Care Medicine, Department of Medicine, National Jewish Health, University of Colorado School of \\ Medicine, Denver, Colorado; and ${ }^{2}$ Division of Pulmonary and Critical Care Medicine, Department of Medicine, University of Michigan Health \\ System, Ann Arbor, Michigan
}

\begin{abstract}
Assessment of patients with chronic obstructive pulmonary disease (COPD) is important to establish an accurate diagnosis, assist in making therapeutic decisions, measuring outcomes for clinical and research purposes, and determining prognosis. Chest computed tomography (CT) scans are useful in patients who present with airflow limitation and clinical features suggestive of COPD but in whom other diagnoses are being considered. In such cases, a chest CT may indicate another diagnosis. The amount and distribution of emphysema can identify outcomes from lung volume reduction surgery, and chest CT scans are mandatory in assessment of patients for this surgery. Quantitative parameters from chest CT scans have been used to define longitudinal progression of disease. Assessment of patients with COPD for both clinical and research purposes should incorporate a variety of different outcomes. There are outcome measures that have been successfully incorporated in large clinical trials, and the design and outcomes of these trials can be used to plan future clinical investigations in COPD.
\end{abstract}

Keywords: chest computed tomography scan; chronic obstructive pulmonary disease; outcomes; health status; exercise capacity

A variety of procedures, tests, and questionnaires can be used to evaluate patients with chronic obstructive pulmonary disease (COPD) for clinical and research purposes. Appropriate assessment of patients with COPD can be used to

1. Make an accurate diagnosis,

2. Assist in making decisions and choices of the most appropriate therapeutic interventions,

3. Measure outcomes in response to interventions in clinical settings and in research investigations, and

4. Provide information about prognosis.

This article will discuss the use of chest computed tomography (CT) scans to assess patients with COPD and review the use of other measures in COPD studies. Because of its size and the large number of outcomes assessed, the National Emphysema Treatment Trial (NETT) will be used to highlight the use of outcome measures in clinical trials (1-3).

\section{MAKING AN ACCURATE DIAGNOSIS OF COPD}

The most widely used current definitions of COPD are provided by two current clinical practice guidelines: he Global Initiative

(Received in original form August 21, 2008; accepted in final form October 20, 2008) Supported in part by National Heart Lung and Blood Institute National Emphysema Treatment Trial contract N01HR76111 (B.J.M.).

Correspondence and requests for reprints should be addressed to Barry J. Make, M.D., National Jewish Health, 1400 Jackson Street, K729, Denver, CO 80206. Email: makeb@njc.org

Proc Am Thorac Soc Vol 5. pp 884-890, 2008

DOI: $10.1513 /$ pats.200808-093QC

Internet address: www.atsjournals.org on Obstructive Lung Disease (GOLD) consensus guideline, and the joint statement by the American Thoracic Society and European Respiratory Society $(4,5)$. A review of the definitions in these guidelines indicates that the major components are similar:

Chronic Obstructive Pulmonary Disease (COPD) is a preventable and treatable disease with some significant extrapulmonary effects that may contribute to the severity in individual patients. Its pulmonary component is characterized by airflow limitation that is not fully reversible. The airflow limitation is usually progressive and associated with an abnormal inflammatory response of the lung to noxious particles or gases. (4)

Chronic obstructive pulmonary disease (COPD) is a preventable and treatable disease state characterized by airflow limitation that is not fully reversible. The airflow limitation is usually progressive and is associated with an abnormal inflammatory response of the lungs to noxious particles or gases, primarily caused by cigarette smoking. Although COPD affects the lungs, it also produces significant systemic consequences. (5)

There is only one criterion required for the diagnosis of COPD: the presence of airflow limitation after an inhaled bronchodilator.

Although not specifically embodied in the definitions nor discussed in detail in the COPD guidelines, optimal clinical practice would dictate that the diagnosis of COPD should only be made after other disorders that are associated with airflow limitation are excluded. History and physical examination may be helpful in excluding other diagnoses and can guide the use of other tests in patients in whom the differential diagnosis includes disorders other than COPD. In addition, the use of chest imaging, particularly chest CT scans, is an important and often overlooked diagnostic tool in COPD when there is a need to exclude other conditions.

When should a chest CT scan be considered by a clinician making a diagnosis of COPD? One group has recently prospectively examined a cohort of patients with COPD to generate a phenotypic definition based on clinical, functional, and chest radiographic criteria; high-resolution CT (HRCT) was subsequently obtained in a subset of subjects (6). Patients could be separated into airway- versus emphysema-predominant phenotypes. Another study segregated 85 patients with COPD using qualitative assessment of HRCT into four groups based on assessment of emphysema and airway disease: (1) without emphysema without bronchial wall thickening $(\mathrm{n}=11)$, (2) without emphysema with bronchial wall thickening $(\mathrm{n}=11),(3)$ emphysema without bronchial wall thickening $(\mathrm{n}=30)$, and (4) emphysema with bronchial wall thickening $(n=31)(7)$. A prospective evaluation of the role of CT scans in the evaluation of all patients presenting with nonreversible limitation and a clinical diagnosis of COPD would be provide useful information to guide clinicians. Such a study would provide information on the utility of CT scans in excluding other conditions. However, we are unaware of such a report. 
Good clinical practice would suggest that a chest CT scan be considered in two distinct clinical scenarios: (1) when the clinician's differential diagnosis suggests there may be a diagnosis other than COPD, and (2) in patients presenting with nonreversible airflow limitation without a history of sufficient environmental or occupational respiratory exposures known to cause COPD. The ATS/ERS COPD statement notes that a chest $\mathrm{X}$-ray is useful in differential diagnosis, and the GOLD guidelines indicate that a chest CT scan may be helpful in differential diagnosis $(4,5)$. Health care practitioners should carefully consider what type of imaging study would provide the most robust information to assist in their clinical differential diagnosis. Disorders that may be included in the differential diagnosis of patients with nonreversible airflow limitation include bronchiolitis, bronchiectasis, panbronchiolitis, chronic respiratory infections or their sequellae, hypersensitivity pneumonitis, asthma, congestive heart failure, lung cancer, lymphangioleiomyomatosis, sarcoidosis, and tracheobronchomalacia $(4,5)$. In many of these conditions (particularly bronchiolitis, bronchiectasis, panbronchiolitis, chronic respiratory infections and their sequellae, hypersensitivity pneumonitis, lung cancer, lymphangioleiomyomatosis [8, 9], sarcoidosis, and tracheobronchomalacia $[10,11])$ chest CT scanning may suggest a diagnosis or even be diagnostic of a condition other than COPD. This is particularly evident in diffuse parenchymal conditions associated with cystic lung disease (12). Interstitial lung disease may also co-exist with COPD, and chest CT scanning is diagnostic of combined disease (13). Since the management of these many of these other disorders differs markedly from the management of patients with COPD, clinicians should be sure they are not overlooking a condition that would result in a different therapeutic approach.

Recent studies suggest that $15 \%$ of patients with COPD do not have a history of cigarette smoking (14-16). Since most patients with COPD most commonly have a history of exposure to cigarette smoke, an argument could be made that most if not all patients with nonreversible airflow limitation who are nonsmokers or do not have an occupational or environmental exposure known to cause COPD should have a chest CT scan to exclude other disorders. However, the utility of this algorithm in clinical practice has not been tested.

\section{THERAPEUTIC DECISION-MAKING IN COPD}

There are two surgical therapies (bullectomy and lung volume reduction surgery) that mandate the use of a chest CT scan to select appropriate patients. While a chest X-ray may suggest the presence of bullae, the presence and extent of such lesions can only accurately be assessed with chest CT scans (17). Similarly, the presence, extent, and distribution of emphysema can most precisely be determined with a chest CT scan.

Early reports of lung volume reduction surgery (LVRS) suggested benefit in patients with upper lobe emphysema (18). The National Emphysema Treatment Trial (NETT) extended these observations, and the results of the NETT form the basis for current selection criteria for $\operatorname{LVRS}(2,3,19)$. In NETT, there were two parameters that determined differential response to treatment: emphysema distribution and exercise capacity.

A chest CT scan is an important tool to determine patients who should not undergo LVRS (19). In NETT, LVRS was associated with a high risk of death $(16 \%$ with LVRS compared with $0 \%$ in subjects treated medically) at 30 days in two types of subjects with emphysema: (1) those with $\mathrm{FEV}_{1}$ of less than or equal to $20 \%$ of predicted and non-upper lobe-predominant disease, and (2) subjects with $\mathrm{FEV}_{1}$ of less than or equal to $20 \%$ of predicted and a diffusing capacity less than or equal to $20 \%$ of predicted. At 6 months, survivors of LVRS compared with medically treated subjects had improvements in walk distance and $\mathrm{FEV}_{1}$, but no improvement in health-related quality of life or exercise capacity. Although there is great interest in quantitative assessment of emphysema using computer scoring systems, CT scan interpretation of emphysema distribution by trained radiologists in NETT was an important outcome marker.

Similarly, the distribution of emphysema on chest CT scan is a marker of the response to LVRS. Subgroups of subjects with emphysema in NETT had differential responses to LVRS. The subgroups were based on radiologist scoring of the distribution of emphysema and exercise capacity (maximum work assessed on an incremental cycle ergometer test). Emphysema distribution was categorized as either upper lobe-predominant or nonupper lobe-predominant; exercise capacity was categorized as high (greater than 40 watts in males and 25 watts in females) or low based on post hoc analyses. The four subgroups with differential outcomes were: (1) upper lobe emphysema and low exercise capacity who had the best outcomes, including improved survival with LVRS; (2) upper lobe emphysema and high exercise capacity who had improved exercise capacity and health-related quality of life with LVRS; (3) non-upper lobe emphysema and low exercise capacity who had improved health-related quality of life and exercise capacity with LVRS; and (4) non-upper lobe emphysema and high exercise capacity who had increased mortality with LVRS (Figure 1).

Given the importance of CT scanning in assessing patients with COPD for potential lung volume reduction surgery that may lead to improved survival, when is a CT scan indicated in patients with COPD? As a starting point, physicians might consider a CT scan in patients with COPD who have an $\mathrm{FEV}_{1}$ of less than or equal to $45 \%$ of predicted. Based on the NETT, clinicians should consider performing a chest CT scan on patients who (1) are clinically suspected of having emphysema, (2) meet NETT inclusion criteria outlined below, and (3) do not have any exclusion criteria for LVRS. Only with the information provided by a chest CT scan, can clinicians evaluate the role of LVRS and have meaningful discussions with their patients about potential surgical intervention.

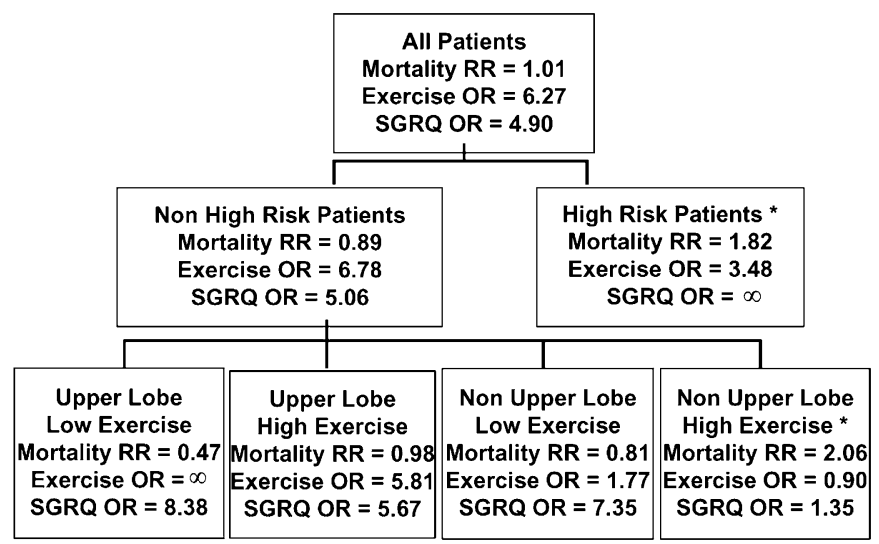

Figure 1. National Emphysema Treatment Trial (NETT) subgroup treatment effects. Effect of lung volume reduction surgery (LVRS) versus medical treatment on mortality, maximal workload achieved on cardiopulmonary exercise testing (improvement of more than 10 watts versus not improved), and disease-specific quality of life as measured by the St. George's Respiratory Questionnaire (SGRQ; improvement of more than 8 units in total score versus not improved). $\mathrm{OR}=$ odds ratio; $\mathrm{RR}=$ relative risk; ${ }^{*}$ Patients not considered candidates for LVRS by the NETT or approved for LVRS by the Centers for Medicare and Medicaid Services or the Joint Commission on Accreditation of Healthcare Organizations. Reprinted by permission from Reference 41. 
Chest CT scans have become an integral part of the evaluation of patients for lung transplantation, as they appear to alter the surgical approach to lung transplantation in selected patients. Kazerooni and colleagues noted that chest CT prompted a change in the determination of which lung was more severely diseased in 27 of 169 patients; of the 45 patients who subsequently underwent transplantation, CT prompted a change in the determination of which side to perform SLT in four (20). Subsequently this group identified pulmonary nodules, suspicious for malignancy, in 8 of 190 patients evaluated for lung transplantation (21). As an active malignancy precludes transplantation, such a finding would clearly alter the candidacy of a patient for lung transplantation. Finally, the presence of unsuspected bronchiectasis could alter the decision to perform DLT in contrast to SLT.

The cost of CT scans should also be considered when making recommendations on the performing the test. The "costs" of CT scans include radiation exposure, time of the patient, and use of medical resources. Medicare reimbursement for a chest CT scan is about $\$ 400$. The costs of performing a chest CT scan on all the 12 million patients in the United States with diagnosed COPD would be about $\$ 4.8$ billion, and based on current evidence could not be justified.

Clinician use of CT scanning in COPD has not been reported. In an effort to evaluate pulmonary specialists' perceptions of the use of CT scans, one of the authors (B.J.M.) surveyed clinicians in his university affiliated medical centers. Two questions were posed: (1) "In what percentage of patients with COPD do you think a chest CT scan should be performed for clinical purposes"? and (2) "In what percentage of patients with COPD and an $F E V_{1}$ of less than $50 \%$ of predicted do you think a chest CT scan should be performed for clinical purposes"? Responses that could be chosen were $25 \%, 50 \%, 75 \%$, and "nearly all." Surveyed pulmonary clinicians responded that $50 \%( \pm 31 \%)$ of all patients with COPD should have a chest CT scan. In response to the second question, pulmonary physicians indicated that $83 \%( \pm 28 \%)$ of patients with COPD and an $\mathrm{FEV}_{1}$ of less than $50 \%$ of predicted should have a chest CT scan.

\section{OUTCOME ASSESSMENT IN COPD}

CT scan-derived data, such as the extent of emphysema and airway disease, can serve as a primary outcome of future clinical trials in COPD. However, in such studies it would also be important to simultaneously assess other outcomes that are clinically relevant, have valid measurement tools that are commonly used, have been employed in previous COPD investigations, and are familiar to health care practitioners. Not all outcome measures meet all these criteria. For example, the $\mathrm{FEV}_{1}$ is commonly used as a lung function outcome in COPD studies and is well known to pulmonary specialists, but is not widely recognized as important to patients. While the FEV can be expected to improve with therapies that target lung function, it may not be a relevant outcome marker for other novel therapies with different targets. In addition, although spirometry testing is well standardized, the minimal clinical important difference has not been rigorously evaluated $(22,23)$. For example, exercise capacity was chosen by the NETT investigators as a key outcome because of its importance to patient overall function (1). Inspiratory capacity is better correlated with changes in exercise capacity than $\mathrm{FEV}_{1}$ and in clinical trials has been shown to be improved in response to currently available medications (24-27).

A variety of constructs can be assessed in response to therapies in COPD, including not only lung function but also physical function, patient-reported outcomes such as health- related quality of life and respiratory symptoms, exacerbation frequency and severity, the course of the disease, systemic consequences, and others. Table 1 provides categorizes outcomes that are important in COPD. It may not be realistic to measure all these outcomes in all clinical trials in COPD. However, the study design should consider assessing multiple outcomes based on the purpose of the study, the nature of the intervention (if any), and the importance of these outcomes to patients with COPD, health care providers, payers of health care costs, and society. A recent ATS/ERS statement made recommendations on the outcomes that should be considered in pharmacologic trials in patients with COPD; those outcomes recommended by the ATS/ERS are noted in Table 1 (28).

The National Emphysema Treatment Trial can serve as a model for assessment of outcomes in future clinical trials in COPD $(29,30)$. This study is used for illustration purposes not only because of the use of CT scans as an inclusion criteria and a marker of outcomes, but also because of the multiple outcomes assessed using a variety of established outcome measures. NETT was a large clinical trial of 1,218 patients designed

TABLE 1. OUTCOMES OF POTENTIAL IMPORTANCE IN CHRONIC OBSTRUCTIVE PULMONARY DISEASE

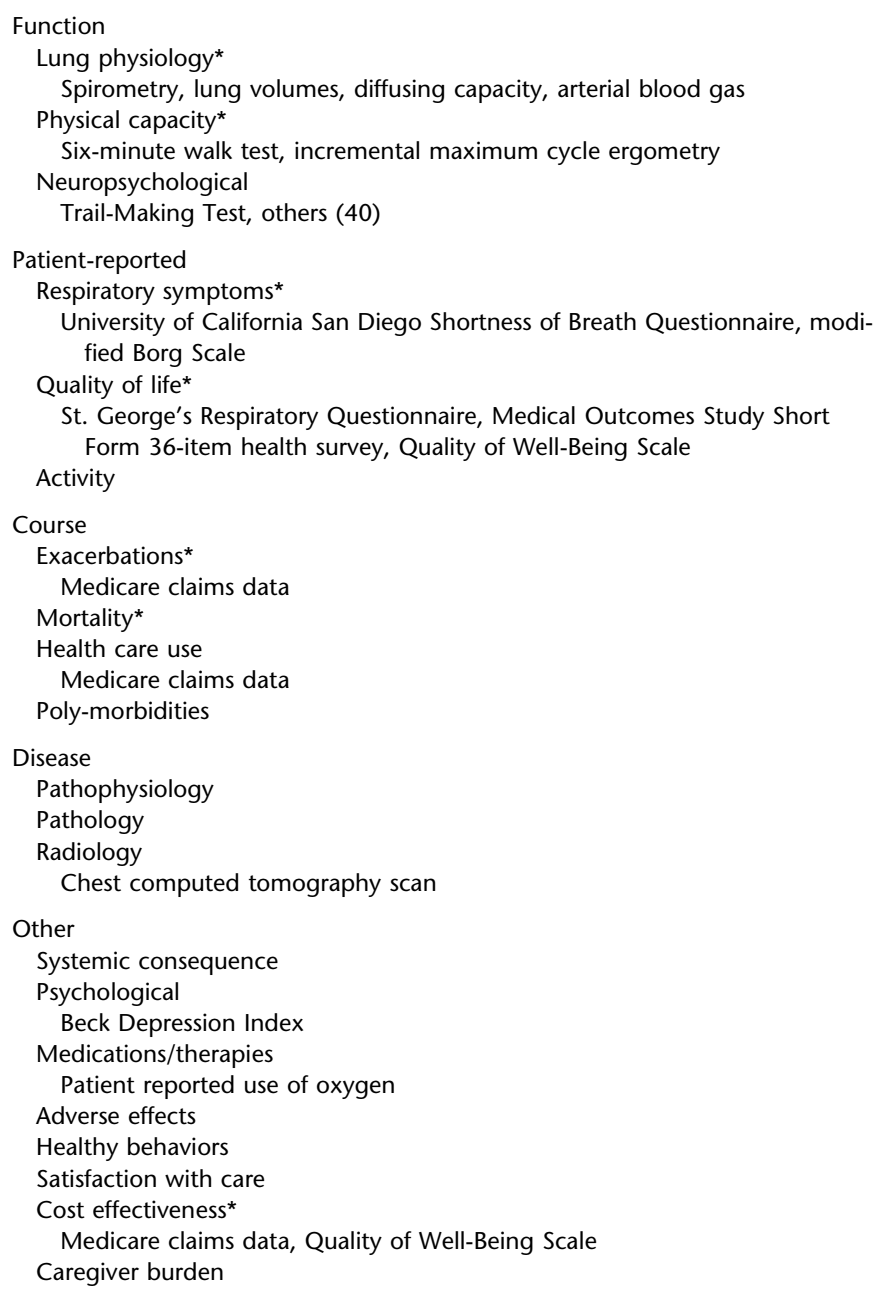

* Recommended for assessment in pharmacologic trials in chronic obstructive pulmonary disease by a task force of the American Thoracic Society and European Thoracic Society (28).

Examples of outcomes are those that were used in the National Emphysema Treatment trial (NETT) (1); other measures are also available to assess these outcomes. Not all outcomes assessed were assessed longitudinally in NETT, and some outcomes were only measured in a subset of subjects. 
to assess the efficacy of lung volume reduction surgery in patients with emphysema (1). Nonsmoking subjects with bilateral moderate-severe emphysema on chest CT scan, moderate-to-severe airflow limitation $\left(\mathrm{FEV}_{1} \leqslant 45 \%\right.$ of predicted), hyperinflation (total lung capacity $\geqslant 110 \%$ of predicted and residual volume capacity $\geqslant 220 \%$ of predicted) were enrolled. Subjects were randomized to either maximal medical therapy, including pulmonary rehabilitation, or to lung volume reduction surgery plus maximal medical therapy.

Before the start of the study, the NETT investigators chose two primary outcomes: survival and exercise capacity. Survival was chosen because it required a large number of subjects and a long-term follow-up, both of which were used to power the study and determine the number of subjects needed for enrollment. The investigators believed that the ability of subjects to increase their performance of activity (assessed by exercise capacity) was an important outcome. Exercise capacity was measured with an incremental maximum cycle ergometry test performed while breathing $30 \%$ inspired oxygen, an outcome and testing methodology not usually employed in clinical trials of COPD. However, the NETT investigators also recognized the importance of measuring a wide variety of other secondary outcomes. For example, health-related quality of life measured by the St. George's Respiratory Questionnaire was a key secondary outcome. A recent issue of this journal reviewed the outcomes and conclusions from the NETT (Proceedings of the American Thoracic Society, Volume 2, Issue 4; May 2008).

The most recent analysis of the NETT showed that survival was improved in all subjects, and subjects with upper lobepredominant emphysema and low exercise capacity had the greatest survival benefit (Figure 2) (3). The investigators had to make a decision about the magnitude of other outcomes that they believed would be clinically significant in response to LVRS. Because the intervention was a major surgical procedure with known mortality and morbidity greater than with medications currently used for the disease, the NETT research group agreed that a clinical benefit equal to twice the generally accepted minimal clinically important difference (MCID) would be the criteria of a successful outcome. For example, the reported MCID for the St. George's Respiratory Questionnaire to assess health-related quality of life is a change of 4 units (31). In NETT, improvement of 8 units was chosen as a clinically important outcome. The reported 5-year follow-up of NETT subjects indicated improved health-related quality of life in all subjects, and the greatest improvement in quality of life was in subjects with upper lobe-predominant emphysema and low exercise capacity (Figure 3).

Longitudinal CT scan data may be useful as outcomes in future therapeutic trials. This is best defined in $\alpha_{1}$-antitrypsindeficient subjects who have accelerated loss of lung function. Progression of emphysema has been documented in these patients over intermediate periods of follow-up (32). Importantly, worsening lung density in these subjects correlates with longitudinal worsening health status (33). Importantly, a small, 3 -year placebo-controlled trial of $\alpha_{1}$-antitrypsin replacement therapy suggested a trend toward preservation of longitudinal markers of CT lung density $(P=0.07)(34)$. A power analysis by these investigators suggested that a protective effect of replacement therapy could be documented by CT lung density in a 130-subject study compared with 550 patients in a study powered on change in $\mathrm{FEV}_{1}$. The ability to document progression of emphysema by HRCT has been confirmed in multiple centers (35). An extension of these concepts has been presented by an investigative group that has documented that annual change in quantitative measures of small airway abnormality correlates with loss of $\mathrm{FEV}_{1}$ in patients with COPD (36).
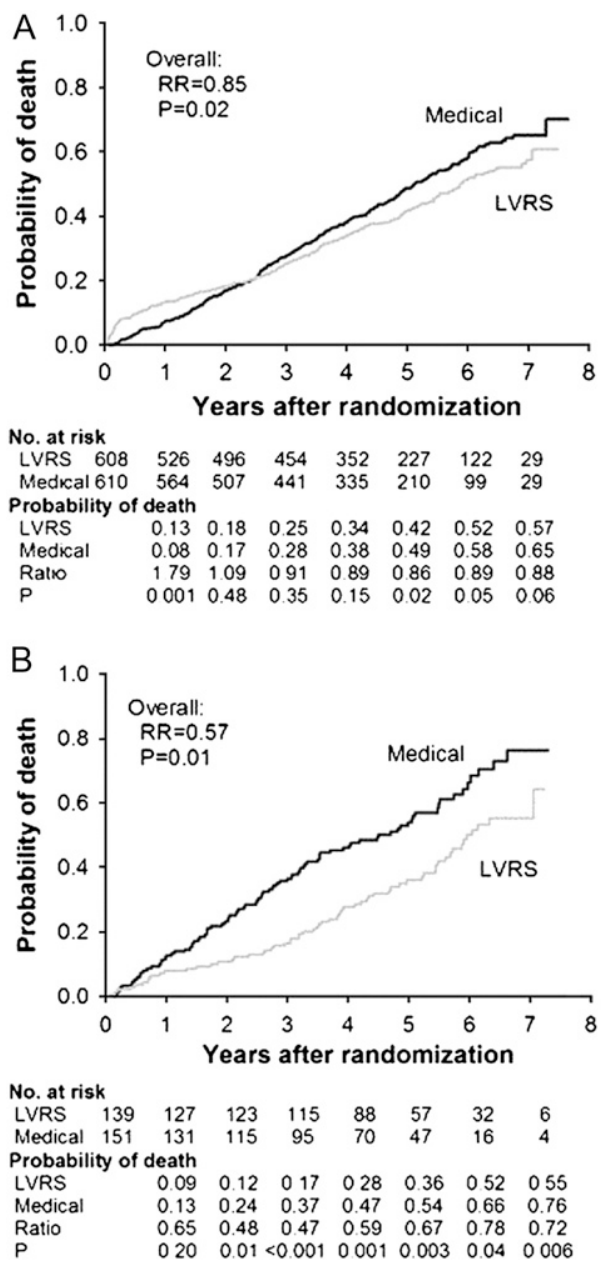

Figure 2. Probability of death in the National Emphysema Treatment Trial. Kaplan-Meier estimates of the cumulative probability of death as a function of years after randomization to lung volume reduction surgery (LVRS) ( gray line) or medical treatment (black line) for $(A)$ all patients and $(B)$ upper lobepredominant and low baseline exercise capacity subgroup. The $P$ value is from the Fisher's exact test for difference in the proportions of patients who died during the 4.3 years (median) of follow-up. Shown below each graph are the numbers of patients at risk, the Kaplan-Meier probabilities, the ratio of the probabilities (LVRS:medical), and $P$ value for the difference in these probabilities. Reprinted by permission from Reference 3 .

In fact, a large Phase II study of a $\gamma$-selective retinoid agonist (TESRA) includes longitudinal assessment of lung density as a pre-specified secondary endpoint (http://www.clinicaltrials. gov/ct2/show/NCT00413205? term $=$ retinoic + acid + AND + emphysemaandrank $=2$ ). It is likely that future studies will be based on longitudinal change in CT parameters.

\section{PROGNOSIS IN COPD}

It has long been recognized that lung function, $\mathrm{FEV}_{1}$, is the single best indicator of survival in patients with COPD (37). However, a more recent study indicated that a multi-composite index (the BODE score) including lung function assessed by $\mathrm{FEV}_{1}$, weight expressed as body mass index, exercise capacity measured by the distance walked in six minutes, and shortness of breath measured by the Modified Medical Research Council Dyspnea Index was a better predictor of survival than $\mathrm{FEV}_{1}$ alone (38).

The utility of the BODE score in predicting survival was confirmed in patients with severe emphysema in the NETT (39). 

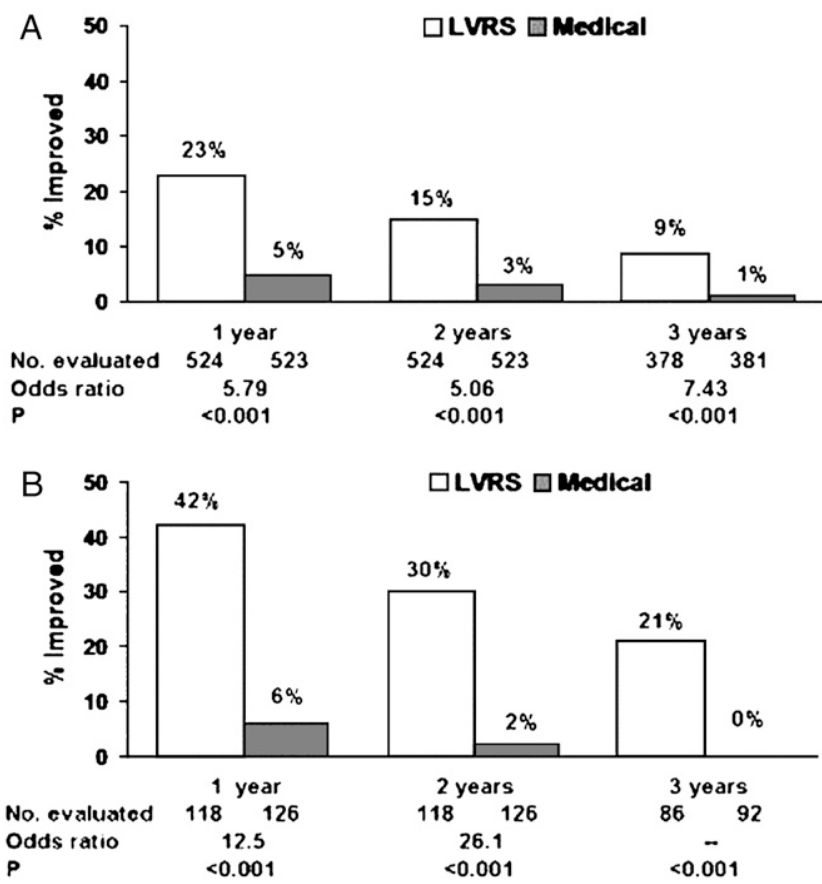

Figure 3. Exercise capacity results from the National Emphysema Treatment Trial. Improvement in exercise capacity (defined as an increase in maximum work of 10 watts above the patient's postrehabilitation baseline) at 1,2, and 3 years after randomization to lung volume reduction surgery (LVRS) (open bars) or medical treatment (shaded bars). Intention to treat analysis of $(A)$ all patients $(n=1,218)$ and $(B)$ upper lobe-predominant and low baseline exercise capacity $(\mathrm{n}=$ 290). Shown below each graph are the numbers of patients evaluated, the odds ratio for improvement (LVRS:medical), and the Fisher's exact $P$ value for difference in proportion improved. Patients who died or who did not complete the assessment were considered not improved (3).

In this study, the six-minute walk distance was replaced by exercise capacity measured on an incremental cycle ergometer. In subjects with a modified BODE score of greater than 7, there was a relative risk of mortality of 1.53 (95\% confidence interval [CI], 1.07-2.05; $P=0.02$ ). On the basis of these studies, it has been suggested that the BODE score be included as an outcome measure in clinical trials of COPD (28).

It seems intuitive that the presence of emphysema would be associated with a worse prognosis than chronic airflow obstruction primarily related to an airway process. The early work of the University of Arizona College of Medicine supports this hypothesis. These investigators examined the survival rate and rate of decline in $\mathrm{FEV}_{1}$ during 10 years of follow up in white, nonMexican Americans with chronic airflow obstruction. Patients with clinical features most consistent with chronic asthmatic bronchitis (a primarily airway process) were contrasted with patients believed to have nonatopic, smoking-related obstructive disease (more consistent with emphysema). The authors found the rate of decline in $\mathrm{FEV}_{1}$ to be greater, and survival to be decreased, in patients with nonasthmatic airflow obstruction.

The presence and severity of emphysema on chest CT scan has not been evaluated as a predictor of survival in unselected patients with COPD. However, in NETT subjects with emphysema, the distribution of emphysema has prognostic significance. Patients with upper lobe-predominant emphysema (a difference in upper lobe versus lower lobe emphysema of $<-0.8$ ) had a 1.80 relative risk of mortality $(95 \% \mathrm{CI}, 1.22-2.66 ; P=0.003)$ in multivariate modeling (Table 2) (39). Of all the prognostic
TABLE 2. SIGNIFICANT PREDICTORS IN MULTIVARIATE MORTALITY MODELS IN PATIENTS $(\mathrm{N}=609)$ WITH SEVERE EMPHYSEMA

\begin{tabular}{|c|c|c|c|}
\hline Predictor & Hazard Ratio & $95 \% \mathrm{Cl}$ & $P$ Value \\
\hline \multicolumn{4}{|l|}{ Age, yr } \\
\hline $70-83$ & 1.72 & $1.31-2.26$ & $<0.001$ \\
\hline $40-69$ & & Reference & \\
\hline $\begin{array}{l}\text { Oxygen use (rest, exercise, or } \\
\text { sleeping) }\end{array}$ & 1.40 & & \\
\hline Yes & 1.40 & $0.98-2.01$ & 0.07 \\
\hline No & & Reference & \\
\hline \multicolumn{4}{|l|}{ Hemoglobin, g/dL } \\
\hline $9.14-13.3$ & 1.38 & $1.00-1.89$ & 0.05 \\
\hline 13.4-19.1 & & Reference & \\
\hline \multicolumn{4}{|l|}{ Total lung capacity, \% predicted } \\
\hline $140-203$ & 0.69 & $0.47-1.01$ & 0.06 \\
\hline 95-139 & & Reference & \\
\hline \multicolumn{4}{|l|}{ Residual volume, \%predicted } \\
\hline $262-412$ & 1.56 & $1.04-2.37$ & 0.03 \\
\hline $97-261$ & & Reference & \\
\hline \multicolumn{4}{|l|}{ DLco } \\
\hline $6-21$ & 1.36 & $1.01-1.84$ & 0.04 \\
\hline $22-68$ & & Reference & \\
\hline \multicolumn{4}{|l|}{ Maximal CPET workload, watts } \\
\hline Low* & 1.48 & $1.12-1.94$ & 0.006 \\
\hline High* $^{*}$ & & Reference & \\
\hline $\begin{array}{l}\text { Difference in \%emphysema } \\
\quad \text { (upper lung-lower lung) }\end{array}$ & 1.80 & $1.22-2.66$ & 0.003 \\
\hline-40.4 to -0.8 & 0.86 & Reference & 0.49 \\
\hline-0.7 to 63.6 & & $0.57-1.31$ & \\
\hline \multicolumn{4}{|l|}{ Missing } \\
\hline \multicolumn{4}{|l|}{ Perfusion ratio } \\
\hline $0.00-0.14$ & 1.53 & $1.11-2.12$ & 0.01 \\
\hline $0.15-3.13$ & & Reference & \\
\hline \multicolumn{4}{|l|}{ Modified BODE index ${ }^{\dagger}$} \\
\hline 7-10 & 1.48 & $1.07-2.05$ & 0.02 \\
\hline $1-6$ & & Reference & \\
\hline
\end{tabular}

Definition of abbreviations: $\mathrm{BMI}=$ body mass index; $\mathrm{Cl}=$ confidence interval; $\mathrm{CPET}=$ cardiopulmonary exercise testing; IC/TLC = ratio of inspiratory capacity to total lung capacity.

Adapted from Reference 35.

All variables listed in Table 2 were included in each model except as noted in the table; results are shown for those variables that were significant predictors at the $P \leqslant 0.05$ level in either model.

* Low exercise is defined as a maximal workload at or below the sex-specific 40th percentile (25 watts for females and 40 watts for males; high exercise is defined as a workload above this threshold.

${ }^{\dagger}$ Components of the modified BODE index are: BMI, FEV ${ }_{1}$, UCSD SOBQ score, and 6MWT distance. $P$ for the four components for the modified BODE index $=$ 0.12 .

features in this study, emphysema distribution was the most important prognostic marker.

\section{CONCLUSIONS}

The first step in the management of patients with COPD is to make the correct diagnosis. A largely unrecognized part of the definition of COPD is the exclusion of other disorders that can be confused with COPD. CT scan assessment of patients with COPD has an important role in assuring a correct diagnosis and thus the most appropriate therapy. Other disorders that can mimic COPD should be excluded on the basis of clinical suspicion and differential diagnosis in each patient.

The current role of CT scanning in assisting with therapy in patients with COPD is confined to surgical interventions, most importantly lung volume reduction surgery. CT scan determination of the extent and distribution of emphysema is a marker for outcomes of LVRS, a therapy that can improve survival in 
patients with upper lobe-predominant emphysema and low exercise capacity. Although not extensively investigated, COPD phenotypes based on chest CT scanning (i.e., the presence and extent of emphysema and airway disease) may potentially be useful in tailoring currently available therapies such as bronchodilators and inhaled steroids. Newer therapies being developed for COPD are targeted to airway disease while other therapies are targeted to emphysema. CT scans may predict patients who may be good candidates for these therapies, and repeated CT scans may provide information about the actual benefit of these agents on airway and parenchymal disease.

Clinical investigations in patients with COPD need to be based on the outcomes that may be achieved. A variety of outcomes are important in COPD, and range from survival to those reported by patients such as the symptom of shortness of breath. Choosing outcome measures that are validated, responsive to change, and meaningful to patients, providers, and society may be modeled on previous reports from large studies such as the National Emphysema Treatment Trial.

The prognosis for patients with severe COPD as identified by the percent predicted $\mathrm{FEV}_{1}$ is poor, but has been difficult to predict in individual patients. Recent studies suggest that the BODE index and distribution of emphysema also provide important prognostic information.

Conflict of Interest Statement: B.J.M. does not have a financial relationship with a commercial entity that has an interest in the subject of this manuscript. F.J.M. is a consultant for Altana Pharma and has received compensation greater than $\$ 10,000$. He has been a member of several Advisory Boards, CME committees, and the Speaker's Bureau for Boehringer Ingelheim and GlaxoSmithKline, with a total compensation per company greater than $\$ 10,000$. In addition, he is on Advisory Boards for Novartis and Genzyme, and on the speaker's bureau for Sepracor, Schering Plough, and Astra, receiving less than $\$ 10,000$ per company. $\mathrm{He}$ has been an investigator for industry-sponsored studies for GlaxoSmithKline, Boehringer Ingelheim, and Actelion.

\section{References}

1. National Emphysema Treatment Trial Research Group. Rationale and design of the National Emphysema Treatment Trial: A prospective randomized trial of lung volume reduction surgery. Chest 1999;116: $1750-1761$.

2. National Emphysema Treatment Trial Research Group. A randomized trial comparing lung volume reduction surgery with medical therapy for severe emphysema. N Engl J Med 2003;348:2059-2073.

3. Naunheim KS, Wood DE, Mohsenifar Z, Sternberg AL, Criner GJ, DeCamp MM, Deschamps CC, Martinez FJ, Sciurba FC, Tonascia J, et al. Long-term follow-up of patients receiving lung-volume-reduction surgery versus medical therapy for severe emphysema by the national emphysema treatment trial research group. Ann Thorac Surg 2006;82: 431-443.

4. Buist AS, Anzueto A, Calverley P, deGuia TS, Fukuchi Y, Jenkins C, Khaltaev N, Kiley J, Kocabas A, Lopez MV, et al. Global strategy for the diagnosis, management, and prevention of chronic obstructive pulmonary disease. 2007. Available from: www.goldcopd.com (accessed October 1, 2008).

5. Celli BR, MacNee W. Standards for the diagnosis and treatment of patients with COPD: a summary of the ATS/ERS position paper. Eur Respir J 2004;23:932-946.

6. Pistolesi M, Camiciottoli G, Paoletti M, Marmai C, Lavorini F, Meoni E, Marchesi C, Giuntini C. Identification of a predominant COPD phenotype in clinical practice. Respir Med 2008;102:367-376.

7. Kitaguchi Y, Fujimoto K, Kubo K, Honda T. Characteristics of COPD phenotypes classified according to the findings of HRCT. Respir Med 2006;100:1742-1752.

8. Sullivan EJ. Lymphangioleiomyomatosis: a review. Chest 1998;114: 1689-1703.

9. Muller NL, Chiles C, Kullnig P. Pulmonary lymphangiomyomatosis: correlation of ct with radiographic and functional findings. Radiology 1990;175:335-339.

10. Lee KS, Sun MR, Ernst A, Feller-Kopman D, Majid A, Boiselle PM. Comparison of dynamic expiratory ct with bronchoscopy for diagnosing airway malacia: a pilot evaluation. Chest 2007;131:758-764.
11. Gilkeson RC, Ciancibello LM, Hejal RB, Montenegro HD, Lange P. Tracheobronchomalacia: dynamic airway evaluation with multidetector CT. Am J Radiol 2001;176:205-210.

12. Koyama M, Johkoh T, Honda O, Tsubamoto M, Kozuka T, Tomiyama $\mathrm{N}$, Hamada S, Nakamura H, Akira M, Ichikado K, et al. Chronic cystic lung disease: diagnostic accuracy of high-resolution CT in 92 patients. Am J Radiol 2003;180:827-835.

13. Cottin V, Cordier JF. Combined pulmonary fibrosis and emphysema: an experimental and clinically relevant phenotype. Am J Respir Crit Care Med 2005;172:1605. (author reply 1605-1606).

14. Cottin V, Nunes H, Brillet PY, Delaval P, Devouassoux G, TillieLeblond I, Israel-Biet D, Court-Fortune I, Valeyre D, Cordier JF. Combined pulmonary fibrosis and emphysema: a distinct underrecognised entity. Eur Respir J 2005;26:586-593.

15. Celli BR, Halbert RJ, Nordyke RJ, Schau B. Airway obstruction in never smokers: results from the third National Health And Nutrition Examination Survey. Am J Med 2005;118:1364-1372.

16. Miravitlles M, Ferrer M, Pont A, Luis Viejo J, Fernando Masa J, Gabriel R, Jimenez-Ruiz CA, Villasante C, Fernandez-Fau L, Sobradillo V. Characteristics of a population of COPD patients identified from a population-based study: focus on previous diagnosis and never smokers. Respir Med 2005;99:985-995.

17. Martinez FJ, Chang A. Surgical therapy for chronic obstructive pulmonary disease. Semin Respir Crit Care Med 2005;26:167-191.

18. Cooper JD, Trulock EP, Triantafillou AN, Patterson GA, Pohl MS, Deloney PA, Sundaresan RS, Roper CL. Bilateral pneumectomy (volume reduction) for chronic obstructive pulmonary disease. J Thorac Cardiovasc Surg 1995;109:106-116. (discussion 116-109).

19. Group NETTR. Patients at high risk of death after lung-volumereduction surgery. $N$ Engl J Med 2001;345:1075-1083.

20. Kazerooni EA, Chow LC, Whyte RI, Martinez FJ, Lynch JP. Preoperative examination of lung transplant candidates: value of chest ct compared with chest radiography. Am J Radiol 1995;165:1343-1348.

21. Kazerooni EA, Hartker FW III, Whyte RI, Martinez FJ, Lynch JP. Transthoracic needle aspiration in patients with severe emphysema: a study of lung transplant candidates. Chest 1996;109:616-619.

22. Donohue JF. Minimal clinically important differences in COPD lung function. COPD 2005;2:111-124.

23. Miller MR, Hankinson J, Brusasco V, Burgos F, Casaburi R, Coates A, Crapo R, Enright P, van der Grinten CP, Gustafsson P, et al. Standardisation of spirometry. Eur Respir J 2005;26:319-338.

24. O'Donnell DE, Fluge T, Gerken F, Hamilton A, Webb K, Aguilaniu B, Make B, Magnussen H. Effects of tiotropium on lung hyperinflation, dyspnoea and exercise tolerance in COPD. Eur Respir $J$ 2004;23: 832-840.

25. O'Donnell DE, Lam M, Webb KA. Measurement of symptoms, lung hyperinflation, and endurance during exercise in chronic obstructive pulmonary disease. Am J Respir Crit Care Med 1998;158:1557-1565.

26. O'Donnell DE, Sciurba F, Celli B, Mahler DA, Webb KA, Kalberg CJ, Knobil K. Effect of fluticasone propionate/salmeterol on lung hyperinflation and exercise endurance in COPD. Chest 2006;130:647-656.

27. Gelb AF, Taylor CF, McClean PA, Shinar CM, Rodrigues MT, Gutierrez CA, Chapman KR, Zamel N. Tiotropium and simplified detection of dynamic hyperinflation. Chest 2007;131:690-695.

28. Cazzola M, MacNee W, Martinez FJ, Rabe KF, Franciosi LG, Barnes PJ, Brusasco V, Burge PS, Calverley PM, Celli BR, et al. Outcomes for COPD pharmacological trials: from lung function to biomarkers. Eur Respir J 2008;31:416-469.

29. Criner GJ, Sternberg AL. National Emphysema Treatment Trial: the state-of-the-art of the evaluation and treatment of emphysema. Introduction. Proc Am Thorac Soc 2008:5:380.

30. Wise RA, Drummond MB. The role of NETT in emphysema research. Proc Am Thorac Soc 2008;5:385-392.

31. Jones PW. St. George's respiratory questionnaire: MCID. COPD 2005;2: 75-79.

32. Parr DG, Sevenoaks M, Deng C, Stoel BC, Stockley RA. Detection of emphysema progression in alpha 1-antitrypsin deficiency using CT densitometry; methodological advances. Respir Res 2008;9:21.

33. Stolk J, Ng WH, Bakker ME, Reiber JH, Rabe KF, Putter H, Stoel BC. Correlation between annual change in health status and computer tomography derived lung density in subjects with alpha1-antitrypsin deficiency. Thorax 2003;58:1027-1030.

34. Dirksen A, Dijkman JH, Madsen F, Stoel B, Hutchison DCS, Ulrik CS, Skovgaard LT, Kok-Jensen A, Rudolphus A, Seersholm N, et al. A randomized clinical trial of $\alpha_{1}$-antitrypsin augmentation therapy. Am J Respir Crit Care Med 1999;160:1468-1472. 
35. Stolk J, Putter H, Bakker EM, Shaker SB, Parr DG, Piitulainen E, Russi EW, Grebski E, Dirksen A, Stockley RA, et al. Progression parameters for emphysema: a clinical investigation. Respir Med 2007;101:1924-1930.

36. O'Hara T, Hirai T, Sato S, Terada K, Kinose D, Haruna A, Marumo S, Nishioka M, Ogawa E, Nakano Y, et al. Longitudinal study of airway dimensions in chronic obstructive pulmonary disease using computed tomography. Respirology 2008;13:372-378.

37. Anthonisen NR. Prognosis in chronic obstructive pulmonary disease: results from multicenter clinical trials. Am Rev Respir Dis 1989;140: S95-S99.

38. Celli BR, Cote CG, Marin JM, Casanova C, Montes de Oca M, Mendez RA, Pinto Plata V, Cabral HJ. The body-mass index, airflow ob- struction, dyspnea, and exercise capacity index in chronic obstructive pulmonary disease. N Engl J Med 2004;350:1005-1012.

39. Martinez FJ, Foster G, Curtis JL, Criner G, Weinmann G, Fishman A, DeCamp MM, Bandit J, Sciurba F, Make B, et al. Predictors of mortality in patients with emphysema and severe airflow obstruction. Am J Respir Crit Care Med 2006;173:1326-1334.

40. Kozora E, Emery CF, Ellison MC, Wamboldt FS, Diaz PT, Make B. Improved neurobehavioral functioning in emphysema patients following lung volume reduction surgery compared with medical therapy. Chest 2005;128:2653-2663.

41. Criner GJ, Sternberg AL. A clinician's guide to the use of lung volume reduction surgery. Proc Am Thorac Soc 2008;5:461-467. 